Gabriel de Oliveira Rodrigues

gaboli@uol.com.br

icenciado em Letras (2000) pela Fundação - Universidade Federal do Rio Grande (FURG); mestre em Ciências da Comunicação/Jornalismo (2007) pela Escola de Comunicações Artes da Universidade de São Paulo (ECA/USP); e doutorando em Linguística/Análise do Discurso no Instituto de Estudos da Linguagem da Universidade Estadual de Campinas (IEL/Unicamp).

\section{Da vergonha à ostentação: um breve ensaio sobre formações discursivas que constroem a memória discursiva sobre o pênis}

From shame to ostentation: a brief essay about discursive formations that build the discursive memory about the

penis

Resumo

Embasado em alguns conceitos da Análise do Discurso francesa e da Psicanálise lacaniana, o presente ensaio pretende abrir uma discussão sobre a memória discursiva em torno de noções de virilidade, e sua representação em imagens do pênis disseminadas tanto pela Arte Ocidental de cultura com origem judaico-cristã, bem como algumas representações na pornografia brasileira contemporânea.

Palavras-chave: Memória discursiva; Pênis; Pintura; Pornografia.

\begin{abstract}
Based on concepts of French Discourse Analysis and the Psychoanalysis by Lacan, the present essay intends to discuss the discursive memory, its concepts of virility and representation through images of the penis spread in the Western Art, culturally based on the Judeo-Christian logic, and in some representations in contemporary Brazilian pornography.
\end{abstract}

Keywords: Discursive memory; Penis; Painting; Pornography. 


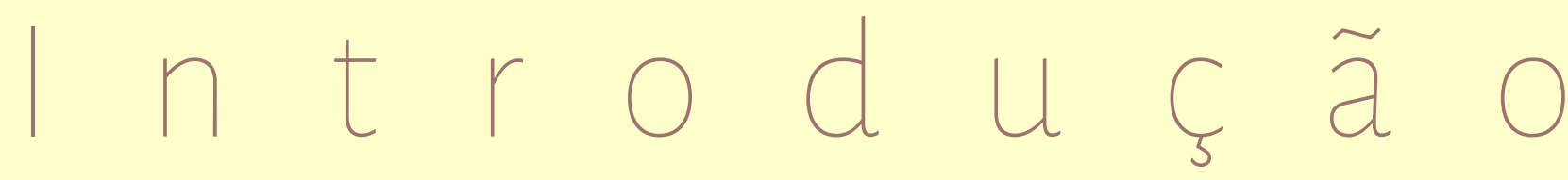

Repetibilidade de representações e memória discursiva

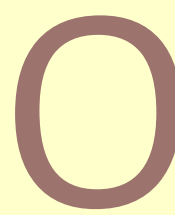

que se conhece por memória em Análise do Discurso (AD), termo cunhado por Jean-Jacques Courtine na década de 1980, possui lugar nos estudos e textos da área desde antes. Termos como repetição e interdiscurso aparecem já em escritos de Michel Pêcheux na década de 1970, remetendo à ideia de memória.

Partindo do princípio que o sujeito, ao tomar a palavra e formular o discurso, ilude-se entendendo ser ele - sujeito a fonte do seu discurso quando, na verdade, os saberes trazidos preexistem ao discurso do sujeito (foram formulados antes, em outro lugar, por outro sujeito), constituindo a noção de repetibilidade. O efeito de esquecimento é o responsável por tal ilusão, funcionando para que o sujeito não tenha consciência de tal repetição de um discurso sempre-já-lá - que Pêcheux chama de pré-construído. Assim, de acordo com a noção de memória discursiva, o sujeito produz seu discurso sob a repetibilidade, mas iludido de ser a origem do saber pelo efeito de esquecimento.

Pierre Achard (2007, p. 13) sustenta que existe a formação de um efeito de série que iniciaria uma regularização na qual residem os implícitos e que funcionaria como dispositivo de recoIhimento destes "sob a forma de remissões, retomadas e efeitos de paráfrase". Assim, entende-se que o implícito é produzido pela repetição, uma série que permite a regularização de certo efeito de sentido.

Tal repetição estabelece uma espécie de regularidade de sentidos, que pode ser quebrada pela incidência de um acontecimento discursivo - que fixaria um novo sentido na memória discursiva. Os saberes e sentidos que circulam socialmente, embebidos na trama sócio histórica, são retomados, repetidos e regularizados pelo/no discurso do sujeito. 
Importante lembrar, ainda, que tais sentidos em circulação não estão petrificados: eles têm a capacidade de escapar das fronteiras das formações discursivas onde se encontram e "deslizar" para outra formação discursiva, inscrevendo outro(s) sentido(s). O todo complexo com dominante das formações discursivas é o que Pêcheux chama de interdiscurso, por onde podem ocorrer tais deslizes de sentido.

Eni Orlandi (1998, p. 21-27) afirma que "as palavras não têm um sentido nelas mesmas porque derivam seus sentidos conforme a memória discursiva em que se inscrevem", ou seja, o sentido das palavras não se encontra nelas mesmas, mas no seu encaixe no discurso, na maneira como a ideologia produz efeitos de sentido materializados no discurso. Com isso, Orlandi indica a existência de um complexo processo de constituição de sujeitos e de produção de efeitos de sentido no funcionamento da própria linguagem, que numa determinada materialidade histórica estabelece relações entre sujeitos e sentidos afetados pela língua e pela história. É por meio da memória discursiva que o discurso constitui os efeitos de sentido entre os sujeitos discursivos, interlocutores.
Falando sobre a leitura de textos, Pêcheux (ACHARD, 2007, p. 52) ressalta que a memória discursiva "vem restabelecer os 'implícitos' (quer dizer, mais tecnicamente, os pré-construídos, elementos citados e relatados, discursos-transversos, etc.) de que sua leitura necessita", possibilitando ao leitor habilitado a capacidade de interligar e (re) construir efeitos de sentido no discurso.

Em 1981, influenciado por todo esse contexto exposto acima, Courtine afirma que "toda produção discursiva faz circular formulações anteriores, porque ela possui em seu domínio associado outras formulações que ela repete, refuta, transforma, denega... isto é: em relação às quais esta formulação possui efeitos de memória específicos" (COURTINE, 1981, p. 52). Assim, nas práticas discursivas, a memória equivale à existência histórica do enunciado regulada pelos aparelhos ideológicos. Isso permite a repetibilidade e, por meio desta, a manutenção de uma memória discursiva socialmente estabelecida, relativamente fixa e formadora de efeitos de sentido que construirão a rede simbólica de significados sobre a qual são possíveis a interlocução e o próprio discurso.

Paralelamente a isso, no campo das ci- 
ências do comportamento, Cornelius Castoriadis, em sua obra intitulada $A$ instituição imaginária da sociedade (1986), discorre sobre as evidências de como os sistemas de organização humana somente podem ser entendidos a partir da relação entre a ordem simbólica e o Imaginário, remetendo diretamente aos registros lacanianos. Castoriadis explica que o Simbólico e o Imaginário têm profundas relações entre si, já que "o imaginário deve utilizar o simbólico não apenas para exprimir-se, mas para 'existir', para passar de virtual a qualquer outra coisa". Inversamente, "o simbólico também pressupõe a capacidade imaginária, para ver em uma coisa o que ela não é, de vê-la diferente do que é" (CASTORIADIS, 1986, p, 154).

O autor salienta que é no Imaginário que uma sociedade procura o complemento necessário para sua ordem, uma vez que no núcleo deste Imaginário é que se encontra um sentido que não é ditado por fatores reais porque, antes disso, é esse Imaginário que confere a esses fatores reais tal importância e tal lugar no universo, ou seja, suas representações. Estes conjuntos de representações que vão se articulan- do - como se fossem uma rede - têm como efeito a construção da realidade em que vivemos, formando uma rede simbólica e, ao mesmo tempo, uma ordem imaginária. Tal ordem rege os lugares representados pelas coisas na sociedade humana; tal ordem rege o sentido de significação dos signos em uso, estabelecendo hierarquias dentro da linguagem.

Assim, conforme o próprio Castoriadis (1986, p. 175), “o imaginário da sociedade [...] determina a escolha [do signo] e as conexões das redes simbólicas [por ele estabelecidas]". O signo em seu uso social ganha vida quando corresponde, no Imaginário da sociedade, à representação de um lugar na rede simbólica ocupado por um "nó", ou referencial. O indivíduo interage quando o signo utilizado no ato comunicativo representa para ele alguma coisa dentro do seu universo de conhecimento, coisa essa socialmente posicionada, coletivamente passível de significação.

Com isso em mente, segue uma breve análise (que mais levanta questionamentos do que respostas) sobre a memória discursiva da virilidade, ou a posição que sua representatividade 
ocupa em dado imaginário social, por meio da representação do papel do pênis em duas formações discursivas socialmente construídas: a pintura e a escultura na Arte Ocidental pós-Niceia e a pornografia brasileira contemporânea. A aproximação destas duas áreas do conhecimento humano - utilizando conceitos da Análise do Discurso de Pêcheux e da Psicanálise de Lacan, que se debruçam sobre o fenômeno da linguagem e construção de sentido-pode indicar caminhos para a compreensão dos efeitos de sentido em representações sociais do órgão genital masculino.

Os dois campos aqui brevemente analisados - arte e pornografia - podem indicar o que é chamado de deslize interdiscursivo: a forma como a representação imagética do pênis nestas duas áreas constrói distintas formações discursivas sobre noções anatômicas do corpo masculino como modelo de virilidade, e seus aspectos na construção da memória discursiva do pênis.

\section{Formações discursivas}

O conceito de formações discursivas nasce em $\mathrm{A}$ arqueologia do saber, de Michel Foucault (2009), e sofre adaptações quando absorvida pelo campo da Análise do Discurso, a partir das ideias de Pêcheux.

Foucault entende as formações discursivas como relações entre enunciados, e lança brevemente quatro hipóteses sobre elas: quando determinado conjunto de discursos se refere a um mesmo objeto; quando as relações se definem pelo estilo (forma e tipo de encadeamento); quando sistemas de conceitos permanentes instituem grupos de enunciados; e quando da formação de eixos temáticos. Tais hipóteses são eliminadas pelo próprio Foucault, esclarecendo que elas não encerram a totalidade da construção de discursos.

No caso em que se puder descrever, entre um certo número de enunciados, semeIhante sistema de dispersão, e no caso em que entre os objetos, os tipos de enunciação, os conceitos, as escolhas temáticas, se puder definir uma regularidade (uma ordem, correlações, posições e funcionamentos, transformações), diremos, por convenção, que se trata de uma formação discursiva (FOUCAULT, 2009, p. 43).

Assim, Foucault propõe a identificação 
das formações discursivas a partir das regularidades por trás da dispersão dos elementos (dispersão com o sentido de diferença). Tais regularidades resultam dos processos de formações discursivas. Vincula-se, assim, o conceito de formações discursivas às instâncias do poder, desenvolvida pelo autor em A ordem do discurso (1996): a formação regular do discurso poderia integrar procedimentos de controle.

Já Pêcheux entende as formações discursivas, a princípio, relacionadas à noção de formação ideológica, principalmente pela influência de Louis Althusser e de sua obra Aparelhos ideológicos do Estado (1983). Partindo de uma premissa marxista, Pêcheux estabelece que

Chamaremos, então, formação discursiva aquilo que, em uma formação ideológica dada, isto é, a partir de uma posição dada em uma conjuntura dada, determinada pelo estado da luta de classes, determina 'o que pode e o que deve ser dito' (articulado sob uma forma de alocução, de um sermão, de um panfleto, de uma exposição, de um programa, etc.) (PÊCHEUX, 2009, p. 160).

Pêcheux (2009, p. 149) sugere que a ideologia se articula por meio dos sujeitos e se materializa por meio do discurso, afinal, "só há ideologia pelo sujeito e para sujeitos". Assim, segundo o autor, todo sujeito é interpelado pela ideologia que o constitui (processo de assujeitamento) e fala a partir de uma formação discursiva ao enunciar, marcando sua posição-sujeito e constituindo uma identidade enunciativa.

Para Charaudeau e Maingueneau (2014, p. 392), "num campo discursivo, 'posicionamento' define mais precisamente uma identidade enunciativa forte ('o discurso do partido comunista de tal período', por exemplo), um lugar de produção discursiva bem específico". Tal identidade mantida entre o sujeito discursivo e a formação discursiva não deve ser compreendida como fixa: Pêcheux (1997, p. 314) diz que "uma FD [formação discursiva] não é um espaço estrutural fechado, pois é constitutivamente 'invadida' por elementos que vêm de [...] outras FDs [e] que se repetem nela, fornecendo-lhe suas evidências discursivas fundamentais", tais como pré-construídos e discursos transversos. Sobre tal base instaura-se o interdiscurso, que possibilita a concretização do discurso pelo sujeito, o qual materializa a ideologia e agencia os sentidos. Conforme já citado neste texto, as palavras não constituem efeitos de sentido em si mesmas, mas no discurso. 
Assim, para Pêcheux (2009, p. 102) toda formação social, constituída de relações entre classes sociais, apresenta "posições políticas e ideológicas, que não são feitas de indivíduos, mas que se organizam em formações que mantêm entre si relações de antagonismo, de aliança ou de dominação" e que possuem as formações discursivas que determinam o que pode e o que deve ser dito. Isso possibilita às palavras mudarem de sentido quando utilizadas em formações discursivas diferentes.

Este trabalho levará em conta duas formações discursivas imagéticas: a Arte Ocidental pós-Niceia, com especial atenção à pintura e à escultura; e a pornografia produzida no Brasil nestes primeiros anos do século 21. O texto enfocará representações do pênis nessas duas formações discursivas, e o papel que tais representações ocupam ideologicamente nos discursos nelas produzidos.

\section{O pênis artístico}

No livro bíblico de Cênesis, possivelmente escrito pelo profeta e legislador hebraico Moisés cerca de 500 anos antes da Era Cristã, registra-se que Adão e Eva, os primeiros humanos, criações diretas do Divino, ao ingerirem o fruto proibido nascido da árvore do centro do Jardim do Éden, teriam se tornado conscientes, tendo conhecimento do que é bom e do que é mau. Antes do fruto, segundo o verso 25 do capítulo 2 do livro de Cênesis, "o homem e a mulher andavam nus e não sentiam vergonha". Após a desobediência e a consciência, diz o mesmo livro, no verso 7 do capítulo 3: "os olhos dos dois se abriram, e perceberam que estavam nus; então juntaram folhas de figueira para cobrir-se" (BÍBLIA, 1992, p. 17).

Assim, a exposição da figura da genitália (tanto masculina quanto feminina) já era motivo de vergonha e da busca de coberturas para mantê-las em segredo. Toda a tradição judaico-cristã tem tais valores como basilares até os dias de hoje, como identificado na pintura de Jan Cossaert, datada do início do século 16 (Imagem 1).

Um pouco mais tarde, na Grécia clássica, ainda não afetada pelos valores judaico-cristãos, a representação do falo na Arte lá produzida trazia conceitos gerais acerca do órgão genital mas- 
culino que influenciariam toda a estética greco-romana. Por extensão, tal influência chegaria a praticamente todo o mundo ocidental como o conhecemos hoje.

O papel da representação social da genitália masculina pode ser notado em uma fala teatral, datada de 400 anos antes da Era Cristã. Aristófanes (1976) escreve a comédia As nuvens, na qual o autor ataca a nova elite ateniense e as propostas pe-

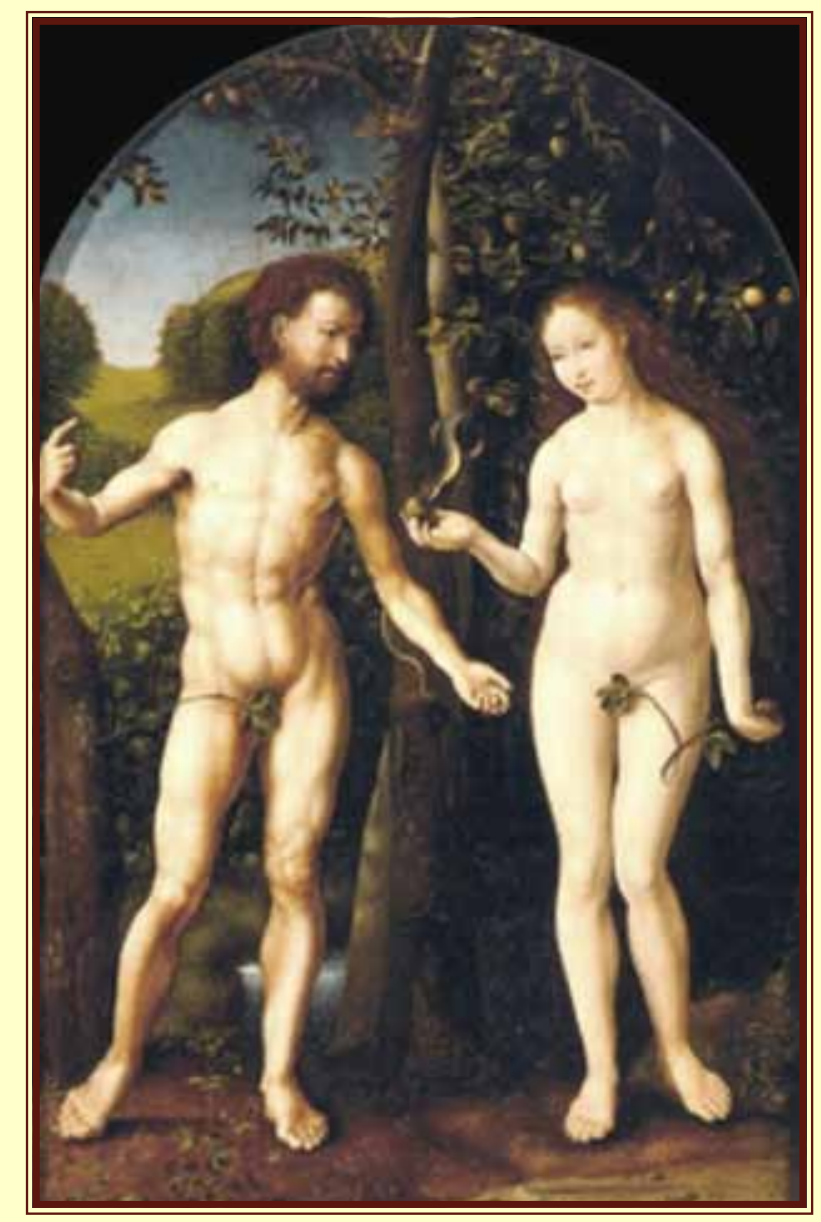

Imagem 1-Adão e Eva, de Jan Cossaert (1507).

Fonte: MUSEU (2016). dagógicas e éticas dos filósofos sofistas, acusando-os de imorais.

Na segunda metade da peça, os personagens Raciocínio Justo e Raciocínio Injusto empreendem uma retórica (tipicamente sofista), sobre o aprendizado. Em determinado momento, o Raciocínio Justo argumenta, sobre os benefícios (em valores físicos e sociais) que os seres humanos teriam ao seguirem seus ensinamentos: "Se fizer o que eu digo e atentar nesses conselhos, terá sempre peito robusto, cores brilhantes, ombros largos, língua curta, quadris grandes e membro pequeno" (ARISTÓFANES, 1976, p. 45, grifo meu). O membro pequeno era sinal de sensatez, segundo os escoliastas - comentaristas que faziam breves anotações sobre os textos com a finalidade de explicá-los ou torná-los mais claros.

Porém, em caso contrário, o mesmo personagem Raciocínio Justo assevera: "Mas se praticar os hábitos de hoje, logo terá pele pálida, ombros estreitos, peito acanhado, língua grande, quadris pequenos, membro comprido e longos decretos... E ele persuadirá você a pensar que tudo que é vergonhoso é belo e o belo, vergonhoso" (ARISTÓFANES, 1976, p. 45 , grifo meu). 
A fala do personagem Raciocínio Justo deixa claro que o porte atlético do corpo masculino saudável incluiria um membro pequeno, um forte sinal de equilíbrio para a estética da época. O contrário, ou seja, um membro comprido, seria sinal do oposto: insensatez, falta de equilíbrio, características notadamente negativas para uma sociedade que privilegiava a razão, tal como o fazia a clássica Crécia.

Com o apogeu do Império Romano e a consequente conquista da Grécia, o contato cultural entre os povos fez com que naturalmente os romanos se apropriassem e adaptassem valores dos gregos, em especial na Arte e na religião. Alie-se esta conjuntura o preponderante papel desempenhado pela Igreja Católica - já como religião oficial do Estado Romano - e suas doutrinas frequentemente reforçadas e/ou renovadas por suas maiores autoridades por meio de suas grandes assembleias.

Cabe ressaltar neste ponto a importância que teve uma das mais famosas dessas assembleias que definiram os caminhos da igreja ao longo dos séculos: o Segundo Concílio de Niceia. Realizado no ano 787 da Era Cristã, este concílio delineou, dentre outros assuntos, quais seriam os pecados capitais, uma classificação das condições humanas utilizada pelo catolicismo com o intuito de controlar, educar e proteger os seus seguidores, para que estes compreendessem e controlassem os instintos básicos do ser humano.

Foram estabelecidos sete pecados capitais, indicados como as origens dos vícios da humanidade: avareza, gula, inveja, ira, preguiça, soberba e luxúria - este último o mais importante para a temática desenvolvida neste texto. Cada pecado capital tem o seu demônio representativo. O demônio da luxúria é Asmodeus (Imagem 2), normalmente representado com asas e três cabeças: uma de homem com hálito de fogo, uma de touro e uma de carneiro, símbolos de virilidade e fertilidade, ressaltando tais representações como aspectos negativos.

A representação do órgão genital masculino, símbolo de virilidade por excelência, é constantemente associada à deterioração humana pelo pecado. Ainda que fortemente condenada pelo clero, tal representação geralmente ganha lugar envergonhado nas grandiosas imagens artisticamente produzidas nos séculos subsequentes ao Segundo Con- 
cílio de Niceia, seguindo os padrões gregos acerca do tamanho do membro.

Com a declaração da luxúria como um dos sete pecados capitais, o mundo ocidental, sob o jugo da religiosidade judaico-cristã, condenou demonstrações explícitas de prazer carnal - o sexo deveria ter como finalidade única a procriação humana, segundo as autoridades religiosas. Isso fez com que a sociedade ocidental

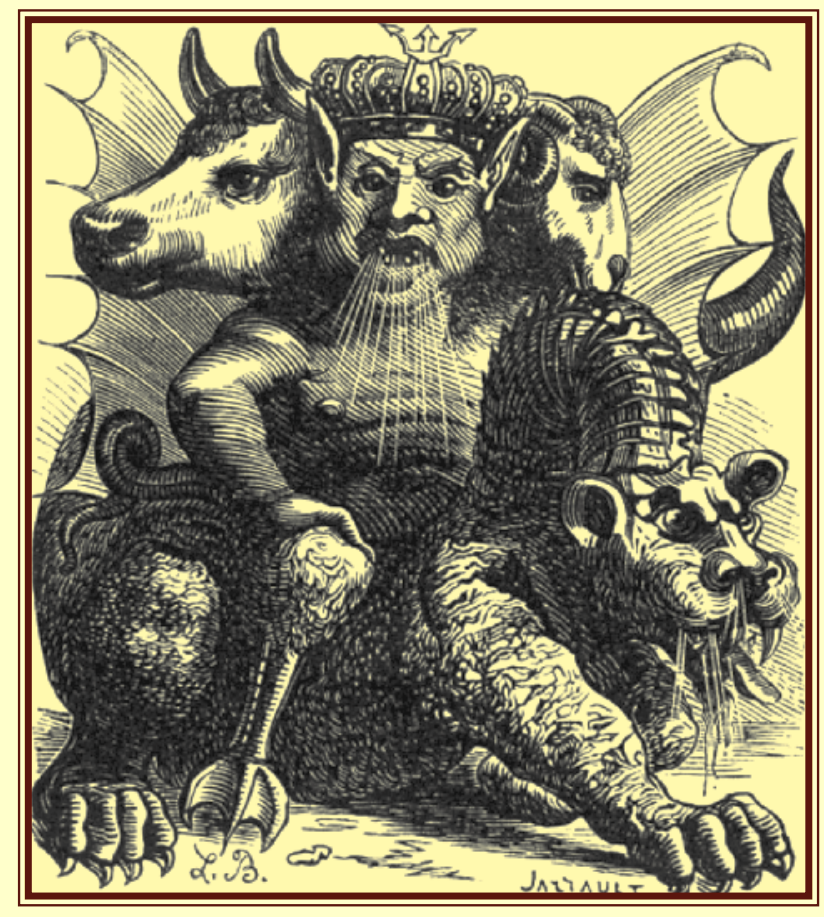

Imagem 2-Asmodeus, o demônio da luxúria (c. 1860).

Fonte: PLANCY, 1863, p. 89. (e naturalmente sua Arte pós-Niceia) passasse a nutrir um "mal-estar" quanto ao pênis.

Freud (1998, p. 42) explica que, com a verticalização do ser humano (o que o
A representação do órgão genital masculino, símbolo de virilidade por excelência,

é constantemente associada à deterioração humana pelo pecado. diferencia dos demais animais), os órgãos genitais masculinos deixam de estar escondidos entre as coxas nas quatro patas e passam e ser visíveis, necessitando de proteção e tornando-se causa de vergonha. Os órgãos femininos continuam escondidos pela convexidade do púbis e seus pelos. Freud ainda salienta que as partes genitais não podem ser julgadas belas, mas apenas excitantes.

Este mesmo mal-estarartístico éapontado também por Denis Diderot. Mencionando os pelos do corpo masculino e as linhas e formas que estes desenham no corpo viril, Diderot (1984, p. 283) identifica:

[A Arte] vos dirá que o caminho dessa linha infinitamente agradável será rompido em seu curso por um tufo interposto; que esse tufo isolado não se liga a nada e causa má impressão na mulher, enquan- 
to que no homem, essa espécie de vestido natural, de sombra bastante espessa nos mamilos, vai clareando-se à verdade nas laterais e nos lados do ventre, mas subsiste, ainda que raro, e vai, sem interromper-se, encontrar-se ela própria mais apertada, mais elevada, mais provida em torno das partes naturais; ela vos mostrará essas partes naturais do homem, despidas como um intestino delgado, um verme de formato bastante desagradável.

\section{O verme de formato bastante desagradá-} vel ao qual Diderot se refere no seu texto é o pênis, um causador de mal-estar da civilização. E nesta formação discursiva, de figura central luxuriosa e excitante, com o peso social de pecado capital, e ainda não devendo ser considerado belo, aproximando-se imageticamente de um verme de formato bastante desagradável, que a figura do pênis vai se tornando cada vez mais marginalizada na memória discursiva.

$\mathrm{Na}$ Arte, a virilidade expressa passa pelo corpo masculino como um todo, pelo vislumbre de corpos nus bem taIhados, mas com o verme desagradável como presença incômoda, censurado pela ausência de beleza e pela imposição religiosa na limitação de ser símbolo luxuriante e pecaminoso de excitação sexual. Abaixo, nas Imagens 3, 4 e 5 , seguem alguns exemplos bem conhecidos da presença envergonhada do pênis na Arte Ocidental pós-Niceia.

\section{A pornografia}

Enquanto a Arte Ocidental pós-Niceia relega à imagem do pênis um não lugar na virilidade (como nas três clássicas imagens anteriores), aparentemente é em outro lugar que o órgão genital masculino performatiza uma construção de sentido dentro da formação discursiva que o coloca como grande joia. No campo da pornografia, o pênis verme de formato bastante desagradável artístico sai de cena, e o enquadramento focaliza em outro sentido para a genitália.

Na contemporaneidade, o sexo é elemento de valorização de mercadorias, servindo de forte chamariz para o imaginário do grande público. Vários materiais cujo carro-chefe é a publicação de material com teor sexual explícito visando à manifestação de prazeres luxuriosos são disponibilizados a todo momento.

De acordo com Laplanche e Pontalis (1995, p. 394-404), em seu Vocabulário 
da Psicanálise, para Sigmund Freud a pulsão é o processo dinâmico que consiste numa pressão ou força que faz o organismo tender para um objetivo. A pulsão sempre tem sua fonte numa excitação corporal (estado de tensão), e sua meta é suprimir o estado de tensão que reina na fonte pulsional. Tal meta será atingida no objeto, ou graças a ele. Daí o papel fundamental da pornografia no processo.

Dentre as pulsões há a pulsão sexual, que é uma pressão interna que atua num campo muito mais vasto que as atividades sexuais. Sua força-motriz é

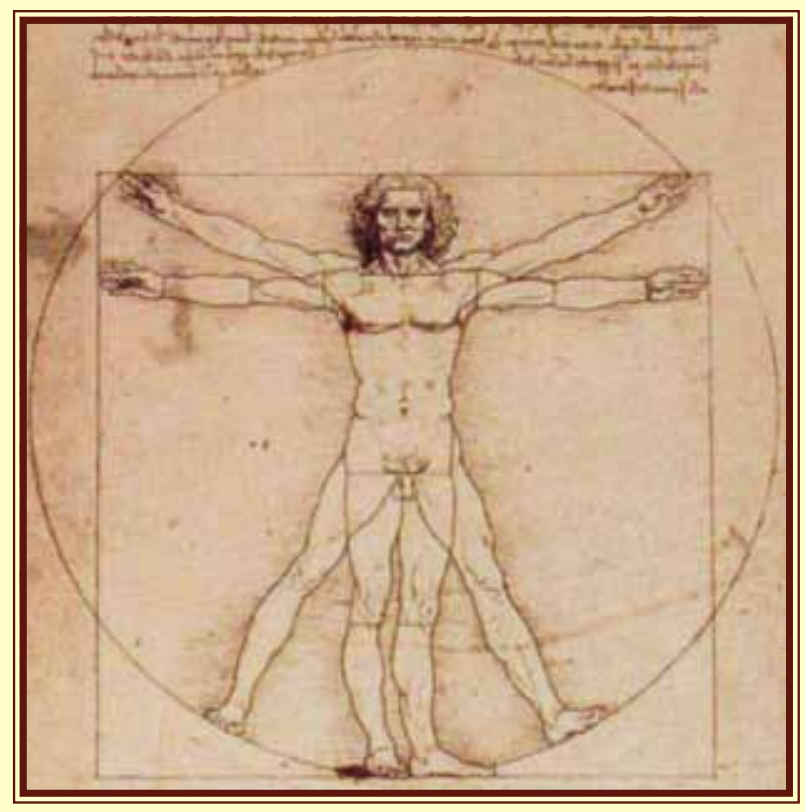

Imagem 3-O homem vitruviano, de Leonardo da Vinci (1490).

Fonte: GALLERIE (2016) a libido, suas metas são variáveis, mais especialmente ligadas ao funcionamento das zonas erógenas, e seu objeto é escolhido em função das vicissitudes da história do sujeito.

Desta forma, cada sujeito naturalmente sofre tensões que o impõem a escolha de um objeto para suprimir a pressão interna. Em um estado de excitação corporal do indivíduo, a libido responde ao contato com o objeto e cria uma demanda a ser suprida. Este objeto não é padronizado, sendo escoIhido a partir da sucessão instável de imprevisibilidades da vida do sujeito.

A moral social vigente, com raízes na religiosidade judaico-cristã, barra o sujeito de sentir determinados prazeres, em especial ligados ao sexo. Práticas sexuais que não visem à reprodução são condenadas como desnaturais. $\mathrm{O}$ agente principal desta condenação são doutrinas religiosas conservadoras, que geralmente classifica os atos sexuais que visam ao prazer como pecaminosos. O pecado capital da luxúria continua firme no imaginário social.

Na contrapartida desta moral, o sujeito em meio à civilização continua 


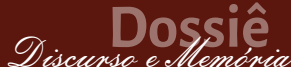

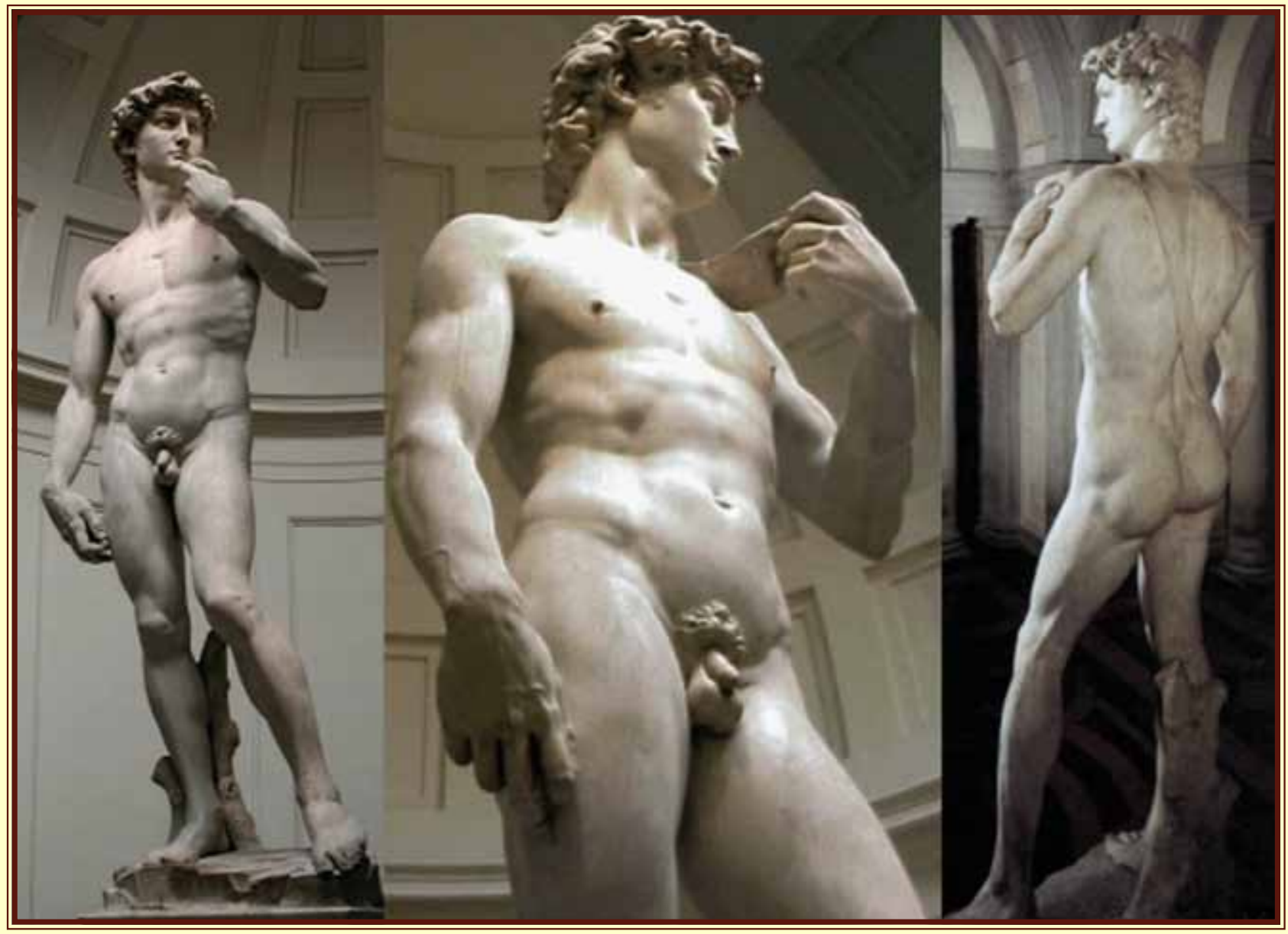

Imagem 4-Davi, de Michelangelo (1504).

$\underline{-}$

Imagem 5-A criação de Adão, de Michelangelo (1511).

Fonte: CUIDE (2016)

Fonte: WEB GALLERY OF ART (2016).

$\nabla$

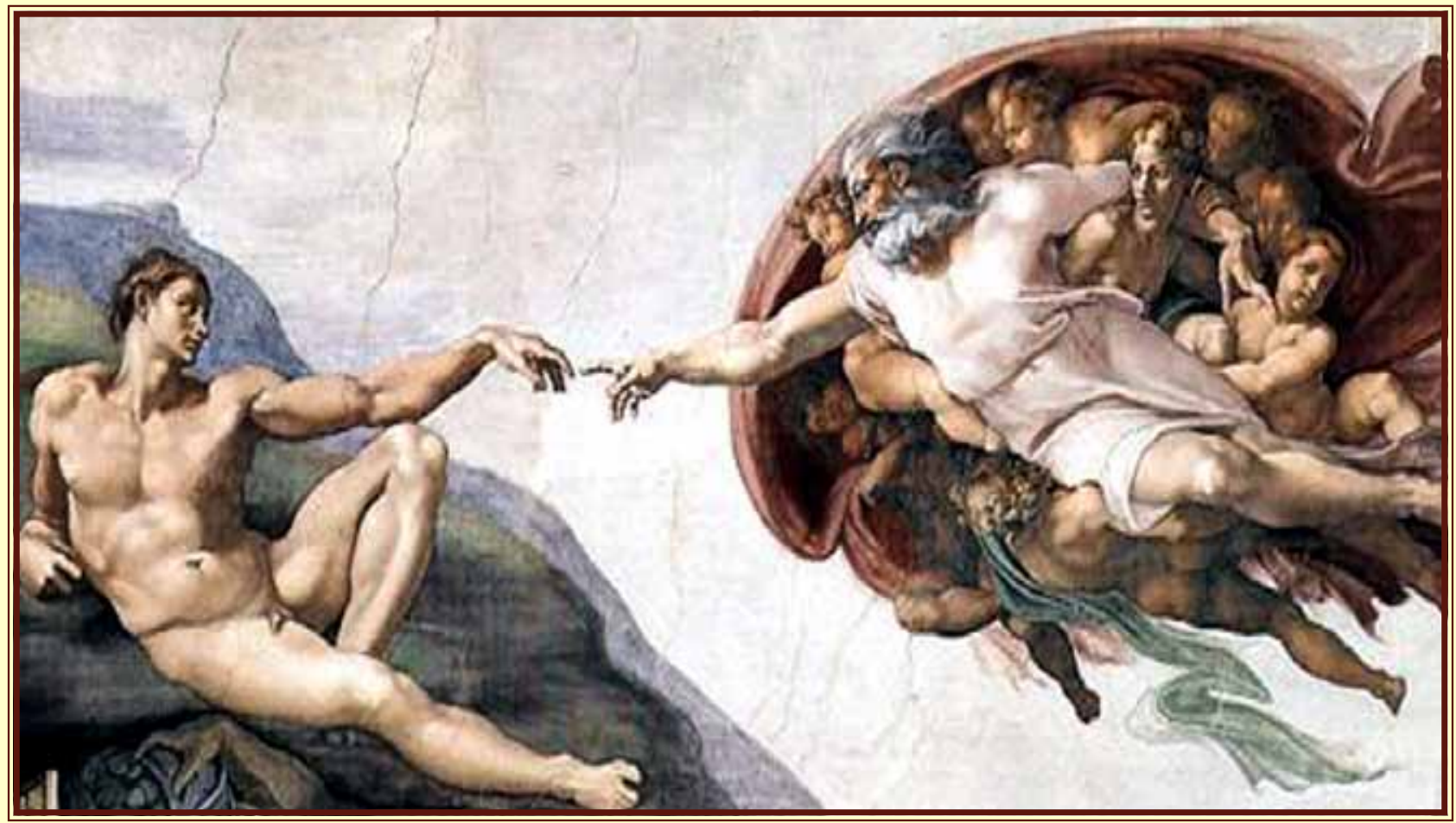


sentindo a tensão que o leva a uma demanda, e procura formas de suprimir a pressão exercida. Então, a própria sociedade encontrou uma solução para este problema e adaptou meios para que o sujeito possa manifestar os prazeres proibidos sem ter de responder pela infração ao código moral.

\section{Em O mal-estar na civilização, Sigmund} Freud (1974) examina, dentre outras coisas, as formas como prazeres barrados pela moral social são desfrutados pelo sujeito, mesmo que de formas um tanto mascaradas. O homem, então civilizado por eclipsar instintos impostos pelo tabu (lei), priva seu ego de externar determinadas formas de prazer, condenáveis aos olhos da moral social, especialmente a judaico-cristã vigente na sociedade ocidental.

Com uma vida na qual os instintos devem permanecer ocultos, aliada à consciência da morte e à trajetória de sofrimento imposta pelo viver, dificilmente o homem produziria felicidade. Assim, a busca pela felicidade transforma-se no objetivo para o viver. Por intermédio desta constante procura, ao homem permite-se, em meio à civilização, demonstrar somente aquelas felicidades aprovadas socialmente.
Mas, os instintos primitivos continuam latentes e desejados, no entanto, não podem ser apresentados com a mesma intensidade com que são produzidos. 0 superego - a consciência - tem o papel de punir tais manifestações, punindo também o simples desejo de manifestar alguns prazeres. Estes permanecem pulsantes no sujeito.

Este sujeito, castrado, privado de seus instintivos sentimentos, busca subterfúgios para suprir as demandas barradas. Hoje, este papel vem sendo desempenhado principalmente pelos meios de comunicação, possibilitando ao sujeito partido inclusive a manifestação de prazer, ainda que não completamente.

A utilização da mídia para manifestação dos prazeres tem sido um caminho viável para a construção discursiva que visa a integrar o sujeito a seu meio social sem que lhe sejam impostas diretamente as morais civilizantes. Através do aprimoramento constante do conhecimento das necessidades de consumo do sujeito, a mídia produz um discurso sempre pronto e presente para amenizar os sofrimentos cotidianos.

O prazer sexual, sem dúvida, entra no jogo de manipulação da mídia, visando 
à satisfação da demanda de prazeres barrados do indivíduo. Tendo em vista o rígido código moral judaico-cristão com relação ao assunto, a sociedade ocidental contemporânea encontra na contemplação midiática um meio de manifestação de prazeres, não sendo diretamente imposta ao sujeito contemplador os ônus de tal manifestação.

A pornografia torna-se a mola propulsora, a ignição que dará partida ao processo de manifestação de um prazer sexual socialmente marcado como fora do padrão moral estabelecido.

das pelo veículo midiático poderá ser manifestado sem um ônus social ao sujeito. A publicação, embebida em significação de profundo teor sexual, está diretamente voltada a atingir sua meta, ligada ao funcionamento das zonas erógenas do sujeito.

A necessidade intrínseca ao ser humano de sentir prazer em meio aos sofrimentos impostos pela

Neste processo de contemplação prazerosa como meio de suprir demandas barradas pela lei inclui-se a pornografia, mídia propagadora de 'imagens proibidas', como objeto por intermédio do qual o sujeito castrado poderá manifestar prazeres a ele barrados.

A pornografia torna-se a mola propulsora, a ignição que dará partida ao processo de manifestação de um prazer sexual socialmente marcado como fora do padrão moral estabelecido. Este mesmo mecanismo funciona nas mídias que publicam o nu feminino.

O prazer sexual advindo do consumo contemplativo de imagens publica- existência impõe a este uma noção incômoda de incapacidade, de incompletude, de falta. Deste sentimento de falta, caracterizador de um sujeito partido, surge a busca por algo que faça o humano sentir-se completo, satisfazendo sua demanda por felicidade.

Em seus Escritos, Jacques Lacan (1992) elaborou sua teoria de que o sujeito, determinado pela linguagem, começa no lugar do Outro. O sujeito partido é, assim, caracterizado pela falta que seria suprida pelo Outro.

Este sujeito falto iniciará uma busca pela completude, busca esta instaurada pela linguagem. O que dá mo- 
vimento à busca (ou, sentido à vida) é a procura pelo falo, que jamais será encontrado. Isso se configura na promessa da posse do falo faltante, que sublimaria a inteireza absoluta, a felicidade completa. Tendo em vista que o falo permanecerá faltante durante toda a vida do sujeito, a promessa jamais será cumprida para o sujeito, pois ninguém consegue obter o suprimento desta demanda, e isso mantém todos os humanos na permanente busca pela felicidade.

Compreender esta procura do sujeito pelo falo faltante é de extrema importância para se entender, segundo Lacan, como funciona a sexualidade. Em Os quatro conceitos fundamentais da Psicanálise (1998), o teórico traça um paralelo antagônico deste sujeito partido na eterna busca pelo falo com a ameba, no que diz respeito à reprodução.

Segundo o autor, a reprodução não sexuada da ameba concede a este ser uma condição de imortalidade: ela não necessita de um Outro para manter-se viva, para sentir-se comple- ta, neste sentido apresentando uma característica de autossuficiência. Tal imortalidade é subtraída do homem pelo fato de ele ser submetido ao ciclo da reprodução sexuada, necessitando do Outro para se reproduzir. A lâmina, que simbolicamente corta esta sensação de inteireza pela perda devida à passagem do homem pelo ciclo sexual, é a libido: esta força que leva o sujeito a procurar a satisfação da sua demanda pelo Outro.

Um dos papéis da pornografia é aguçar a necessidade de suprimento pela demanda causada pela falta do falo. Pretendendo ocupar um papel de detentora do falo, a mídia pornográfica disponibilizaria uma nuance da posse deste. Ao mesmo tempo que instiga a necessidade do suprimento por atiçar a libido dos leitores, esta mídia provê um vislumbre da posse do falo por meio da exibição dos prazeres proibidos.

Como pretensa detentora do falo, a pornografia poderia oferecê-lo aos sujeitos partidos que por ele buscam, tornando-se disseminadora de prazeres proibidos, 
mecanismo por meio do qual leitores manifestariam seus desejos barrados socialmente. Esta mídia desencadearia nestes sujeitos o processo de manifestação de instintos sexuais moralmente reprováveis, reforçando a promessa da completude (nunca) atingida pela (impossível) posse do falo.

O termo fetiche é empregado por diversas áreas. Emprestado da antropologia, nas ciências do comportamento ele designa um substituto mágico do falo faltante. Segundo David Zimerman (2001, p. 149), em seu Vocabulário contemporâneo de Psicanálise, o fetiche para Freud era "uma perversão sexual caracterizada pelo fato de uma parte do corpo [...] ou um objeto exterior [...] serem tomados como objetos exclusivos de uma excitação ou prática perversa de atos sexuais".

Importante salientar que estes objetos são tomados como exclusivos de uma excitação, ou seja, cumprem o papel de atiçar a libido do sujeito que identifica nele um meio de reprimir a sua tensão. No processo de significação desencadeado pelo sujeito, os objetos tomam significações essencialmente sexuais e, uma vez atiçados pela libido, cau- sam no organismo do indivíduo uma reação de excitação.

É pelo consumo do material, é pela admiração dos corpos nus nas sequências fotográficas estampadas nas páginas da revista que o sujeito poderá manifestar seu prazer. O contato visual com a pornografia, respondendo momentaneamente à demanda da manifestação de prazer incitada pela libido, faz da mídia um fetiche sexual para o sujeito que apresenta esta reação, por ser um objeto inanimado por meio do qual um fetichista manifesta seu prazer, supre sua demanda dotando-o de significação sexual.

\section{O pênis pornográfico}

Segundo Pierre Guiraud (1991, p. 50), "a ereção peniana, em correlação com os temas do 'alto e do baixo', do 'erguido e do curvado', do 'duro e do mole', constituem os símbolos privilegiados da superioridade social e da vontade de poder".

Nesta segunda formação discursiva 
acerca da virilidade, o pênis desempenha papel fundamental. Para além da funcionalidade procriativa, há correlações imagéticas de formas e direções que constroem discursivamente $\mathrm{o}$ sentido que o phnis viril concede a quem o ostenta. O mesmo Guiraud Para além da funcionalidade procriativa, há correlações imagéticas de formas e direções que constroem discursivamente o sentido que o pênis viril concede a quem o ostenta. da primeira década dos anos 2000, publicou-se no Brasil a G Magazine, revista brasileira mensal voltada para o público gay e cujo carro-chefe era um ensaio fotográfico de nu masculino. As sequências de imagens destes ensaios em C Magazine tinham por característica peculiar salienta que "a etimologia confunde em uma mesma imagem a ideia de 'endireitamento vertical' (erigir, ereção, endireitar, latim directiare etc.) e a de comando (dirigir, diretor, rei, latim rex)".

Tal pênis deve ostentar uma imagem de comando, de indicar de direção. Deve ser não apenas funcional, mas também possuir uma determinada estética específica, que talvez agrade determinadas audiências de voyeurs e contradiga, de certa forma, Freud e sua negação da beleza do órgão genital. Ou seja, nesta formação discursiva, o pênis, longe de se apresentar como verme desagradável, é símbolo discursivo do poder daquele que o ostenta.

Entre o fim dos anos 1990 e ao longo a exibição de seus protagonistas com ereção peniana, sendo esta uma clara demonstração de poder, de comando, de ação. Abaixo seguem dois exemplos de fotografias publicadas pela revista (Imagens 6 e 7).

O protagonista dos ensaios de C Magazine é o rei, aquele que detém o poder, aquele que decide, que comanda, aquele a quem o espectador está subjugado. O rei-sedutor se exibe e domina, toma conta da situação submetendo o olhar do espectador-seduzido. A relação estabelecida entre eles é de subjugo. Estabelece-se a relação de domínio do poderio do masculino viril representado pelo falo. O espectador é seduzido pelo poderoso exibicionista, o qual se produziu para representar 
imageticamente certa formação discursiva sobre a virilidade: o pênis-símbolo-máximo é objeto de deslumbramento, jamais de vergonha.

O protagonista dos ensaios de $\mathrm{C}$ Magazine é o rei, aquele que detém o poder, aquele que decide, que comanda, aquele a quem o espectador está subjugado. O rei-sedutor se exibe e domina, toma conta da situação submetendo o olhar do espectador-seduzido. A relação estabelecida entre eles é de subjugo. Estabelece-se a relação de

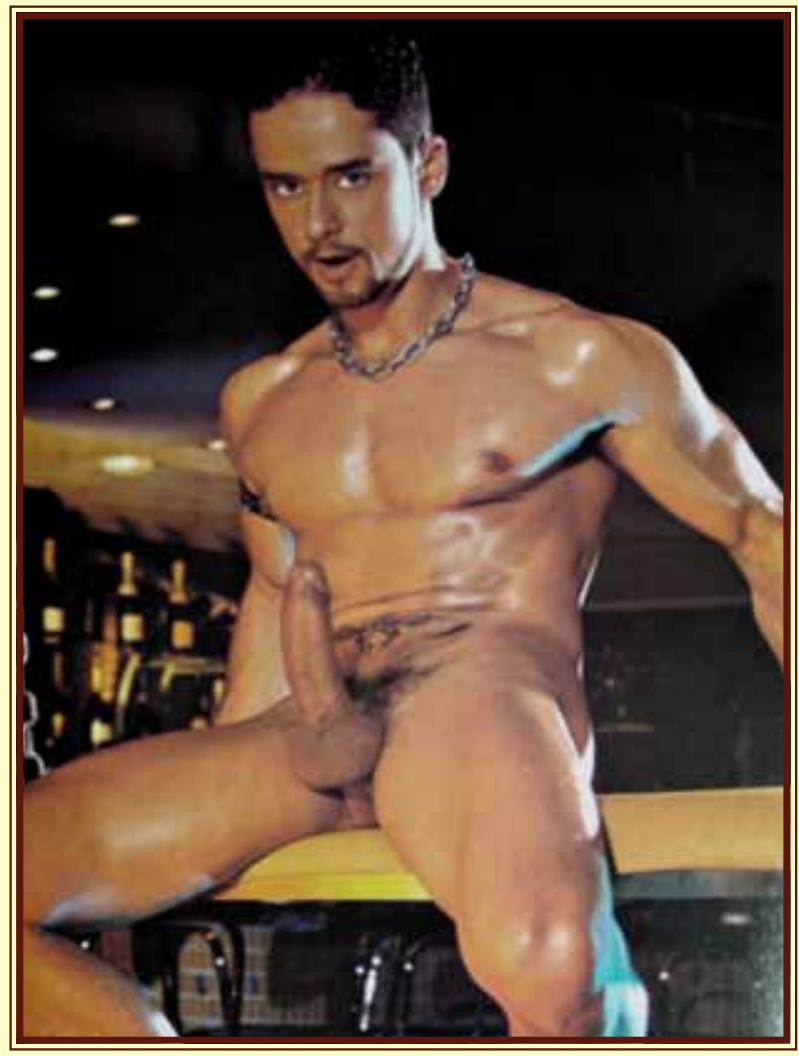

Imagem 6-Ensaio de Rafael Alencar.

Fonte: G MACAZINE (2003, p. 36). domínio do poderio do masculino viril representado pelo falo. O espectador é seduzido pelo poderoso exibicionista, o qual se produziu para representar imageticamente certa formação discursiva sobre a virilidade: o pênis-símbolo-máximo é objeto de deslumbramento, jamais de vergonha.

O corpo-signo é sinal de poder, em especial quando acompanhado da sim-

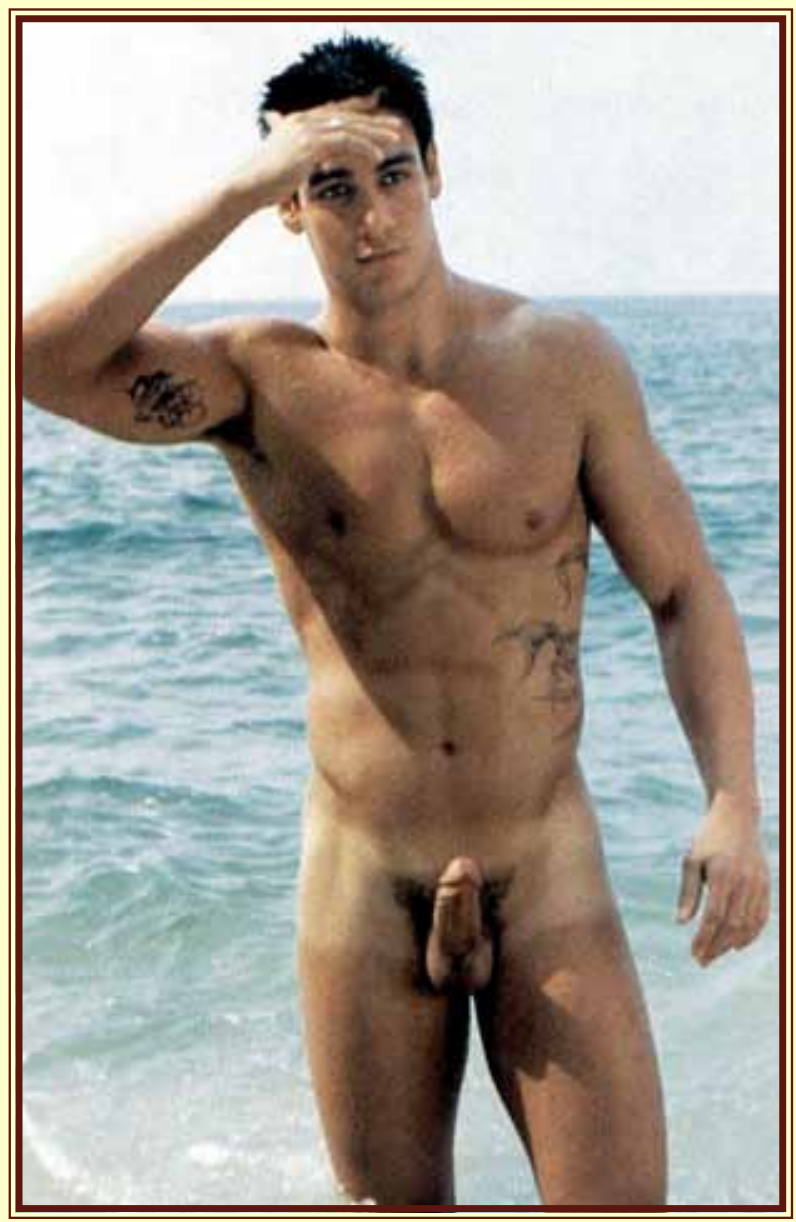

Imagem 7-Ensaio de Rafael do Acorrentados.

Fonte: C MACAZINE (2002, p. 30) 
bologia divina de demonstração de poder-o pênis. A noção de grandiosidade e poderio exposta pelo protagonista do ensaio de GMagazineé, em linhas gerais, a mesma das arquiteturas pomposas de templos das mais variadas instituições religiosas mundo afora. As formas de demonstração de poder seguem uma mesma linha imagética. Ambas seguem o direcionamento de representação da posse do poder. O falo é o símbolo do poder, e seu proprietário-que vai se preparar, se produzir para exibir seu poder - torna-se digno de idolatria, como um deus.

Por meio das sequências fotográficas publicadas mensalmente em suas páginas, G Magazine constrói seu discurso oferecendo a seus leitores uma linguagem que mantém o "lugar do pênis" na rede simbólica. Na sua quase totalidade, as sequências de fotografias mostram um pênis rígido, ereto, nunca flácido ou aparentemente abatido. Esta disposi- ção imagética legitima, de forma geral, a noção de poder atribuída socialmente ao pênis e, especialmente, ao seu portador, o masculino. Instauram-se, assim, discursivamente os jogos entre poderes e prazeres designados por Michel Foucault, que outorgam ao macho detentor do símbolo de poder o privilégio de gozar prazeres barrados àqueles que não são possuidores daquele símbolo e estão, portanto, fora do eixo de poder.

Assim, o pênis pornográfico mostra-se exibidamente bem diferente do pênis na Arte em geral. Totalmente desavergonhado, faz questão de ostentar valores que se contrapõem inclusive ao equilíbrio do membro pequeno pensado pelos gregos.

\section{Considerações finais}

Este ensaio, longe de almejar exibir 
pontos inquestionáveis acerca do papel imagético do pênis em diferentes formações discursivas, deseja presentar formações discursivas paralelas acerca da virilidade, e a posição da imagem do pênis como construção de sentido dessa(s) ideia(s) de virilidade socialmente difundida(s).

A memória discursiva do pênis na formação discursiva do campo da Arte parece construir um discurso mais envergonhado, tímido, não ocupando papel de protagonista, escondendo-se como um verme o qual deve ser escondido, motivo de desgraça. Mesmo quando exibido, deve ser apresentado como membro pequeno, para evitar associações com desregramentos morais baseados nos valores judaico-cristãos.

Já a memória discursiva do pênis na formação discursiva do campo da pornografia parece construir um discurso bem mais altaneiro, altivo, ocupando papel principal na demonstração da virilidade, exibindo-se como troféu a ser orgulhosamente ostentado por seu portador. Sua representação deve preferencialmente ser ereta, erguida, para cima, associando-se ao domínio do eixo de poder.

As linguagens utilizadas nas duas for- mações discursivas para apresentar "dadas realidades" foram moldadas na instância do simbólico pelo manuseio do corpo-signo, em especial da representação do pênis, que influencia diretamente na estrutura ilusória construída imaginariamente. As noções de posse e demonstração de poder intrínsecas à disposição anatômica do corpo, bem como à exibição do pênis, em repouso ou ereto, por um protagonista direcionam a visão imaginária social.

A repetibilidade de determinada representação como formação discursiva, fazendo circular formulações anteriores associadas a ela, naturalmente permite a manutenção de memórias discursivas socialmente estabelecidas, relativamente fixas e que formam efeitos de sentido na construção da rede simbólica de significados. Tal fenômeno ocorre com as representações do pênis nas dadas realidades: a artística e a pornográfica.

Os dois campos aqui brevemente expostos, a Arte Ocidental pós-Niceia e a pornografia contemporânea, parecem demonstrar justamente um exemplo de deslize interdiscursivo entre duas formações discursivas que imageticamente trabalham com noções anatô- 
micas do corpo masculino como modelos de virilidade.

A representação artística do pênis como símbolo viril parece indicar uma repetibilidade mais discreta, como parte de um conjunto mais contextualizado, enquanto a representação pornográfica do pênis como referencial de virilidade necessariamente precisa mostrar o órgão em posição anatômica de exibição de funcionalidade sexual, como foco central da imagem e objeto de desejo.

Mas, há exceções nas formações discursivas dentro das áreas específicas discutidas acima. Há manifestações artísticas de pênis eretos, bem como imagens pornográficas de pênis fláci- dos. Ambas iriam contra os efeitos de sentido geral das áreas, da exibição do belo e da potência, respectivamente. Daí uma dificuldade em se determinar com exatidão uma fronteira: quando uma representação do pênis é artística e quando é pornográfica? O que a faz Arte e o que a faz pornografia? Seria a dicotomia flacidez/ereção? O quanto tais repetibilidades fortalecem formações discursivas que embasam a existência de memória discursiva sobre o pênis? O quanto tais representações simbólicas constroem o Imaginário social acercado órgão genital masculino?

Que o presente texto possa embasar discussões sobre o tema e auxiliar na construção de novos conhecimentos acerca de tão complexa área: o discurso.

\section{Referências}

ACHARD, Pierre et al. Papel da memória. Tradução de José Horta Nunes. Campinas: Pontes, 2007.

ALTHUSSER, Louis. Aparelhos ideológicos do Estado. Rio de Janeiro: Craal, 1983.

ARISTÓFANES. As nuvens. Tradução de Junito de Souza Brandão. Rio de Janeiro: Crifo, 1976. 
BÍBLIA. Português. Bíblia de Referência Thompson. Tradução de João Ferreira de Almeida. Edição revista e corrigida. Compilado e corrigido por Frank Charles Thompson. São Paulo: Vida, 1992

CASTORIADIS, Cornelius. A instituição imaginária da sociedade. São Paulo: Paz e Terra, 1986.

CHARAUDEAU, Patrick; MAINCUENEAU, Dominique. Dicionário de análise do discurso. 3. ed. São Paulo: Contexto, 2014.

COURTINE, J. J; MARANDIN, Jean-Marie. Quel objet pour l'analyse du discours? In: CONEIN, Bernard et al. Matérialités discursives. Lille: Presses Universitaires, 1981. p. 21-33.

DIDEROT, Denis. Salon de 1765. Paris: Hermann, 1984.

FOUCAULT, Michel. A arqueologia do saber. Rio de Janeiro: Forense Universitária, 2009. A ordem do discurso. 3. ed. São Paulo: Loyola, 1996.

FREUD, Sigmund. O mal-estar na civilização. In: Obras psicológicas completas de Sigmund Freud. Rio de Janeiro: Imago, 1974. v. 23.

G MACAZINE. São Paulo: Fractal Edições, n. 57, jun. 2002.

G MAGAZINE. São Paulo: Fractal Edições, n. 72, set. 2003.

CALLERIE DELLACCADEMIA DE VENICE. Leonardo da Vinci-The universal man. Disponível em: $<$ http://www.gallerieaccademia.it/leonardo-da-vinci-universal-man-gallerie-dellaccademia-venice >. Acesso em: 28 ago. 2016.

CUIDE TO THE ACCADEMIA GALLERY IN FLORENCE. Michelangelo's David. Disponível em: <http://www.accademia.org/explore-museum/artworks/michelangelos-david/>. Acesso em: 28 ago. 2016.

GUIRAUD, Pierre. A linguagem do corpo. São Paulo: Ática, 1991. (Série Fundamentos; 70). 
LACAN, Jacques. Escritos. São Paulo: Perspectiva, 1992.

Seminário XI: Os quatro conceitos fundamentais da Psicanálise. Rio de Janeiro: Jorge Zahar, 1998.

LAPLANCHE, J.; PONTALIS, ]. B. Vocabulário da Psicanálise. São Paulo: Martins Fontes, 1995.

MUSEU THYSSEN-BORNEMISZA. Thyssen-Bornemisza Collection. Disponível em: <http://wwwmuseothyssen.org/en/thyssen/ficha_obra/369>. Acesso em: 28 ago. 2016.

ORLANDI, Eni Puccinelli. Discurso e argumentação: um observatório do político. Fórum linguístico, Florianópolis, n. 1, p. 73-81, jul./dez. 1998.

PÊCHEUX, Michel. Semântica e discurso: uma crítica à afirmação do óbvio. Tradução de Eni Orlandi et al. Campinas: Editora da Unicamp, 2009.

PLANCY, J.A.S. Collin de. Dictionnaire infernal. Paris: Plon, 1863.

WEB GALLERY OF ART. A criação de Adão. Disponível em: <http://www.wga.hu/art/m/ michelan/3sistina/4ceilin2.jpg>. Acesso em: 28 ago. 2016.

ZIMERMAN, David. Vocabulário contemporâneo de Psicanálise. Porto Alegre: Artmed Editora, 2001. 